\title{
Long-term outcome of revascularization with composite T-grafts: Is bilateral mammary grafting better than single mammary and radial artery grafting?
}

\author{
Dmitry Pevni, MD ${ }^{\mathrm{a}, \mathrm{c}}$ Rephael Mohr, MD ${ }^{\mathrm{a}, \mathrm{c}}$ Yosef Paz, MD, ${ }^{\mathrm{a}, \mathrm{c}}$ Amir Kramer, MD, ${ }^{\mathrm{a}, \mathrm{c}}$ Yanai Ben-Gal, MD, ${ }^{\mathrm{a}, \mathrm{c}}$ \\ Nahum Nesher, $\mathrm{MD},{ }^{\mathrm{a}, \mathrm{c}}$ and Benjamin Medalion, $\mathrm{MD}^{\mathrm{b}, \mathrm{c}}$
}

\begin{abstract}
Objective: Bilateral internal mammary artery (BIMA) grafting is associated with improved survival. However, many surgeons are reluctant to use this technique, owing to the potentially increased risk of sternal infection. The composite T-graft with radial artery (RA) attached end-to-side to the left internal mammary artery (IMA) provides complete arterial revascularization without increased risk of sternal infection. The purpose of this study is to compare outcomes of these 2 strategies.
\end{abstract}

Methods: Patients who underwent BIMA grafting using the composite T-graft technique, between 1996 and $2010(\mathrm{n}=1329)$, were compared with 389 patients who underwent composite grafting with a single IMA + RA during the same time period.

Results: Patients undergoing single IMA grafting were older, more often women, and more likely to have diabetes, peripheral vascular disease, and COPD, and to need an emergency operation. Congestive heart failure, left main disease, and recent myocardial infarction were more prevalent with bilateral grafting. Propensity-score matching was used to account for differences between groups in preoperative patient characteristics. The 268 matched pairs had similar characteristics.

The median follow-up time was 14.19 (95\% confidence interval 13.43-14.95) years. Operative mortality and Kaplan-Meier 10-year survival of the 2 matched groups were similar $(3.4 \%$ vs $3.7 \%$, and $61.6 \%$ vs $64 \%$, for the groups treated with BIMA and single IMA, respectively). Cox-adjusted survival was similar $(P=.514)$. Age, chronic renal failure, and performance of $<3$ bypass grafts were independent predictors of decreased survival.

Conclusions: This study suggests that long-term outcomes of arterial revascularization with a composite T-graft constructed using left IMA and RA are not inferior to outcomes after BIMA grafting. (J Thorac Cardiovasc Surg 2016;151:1311-9)

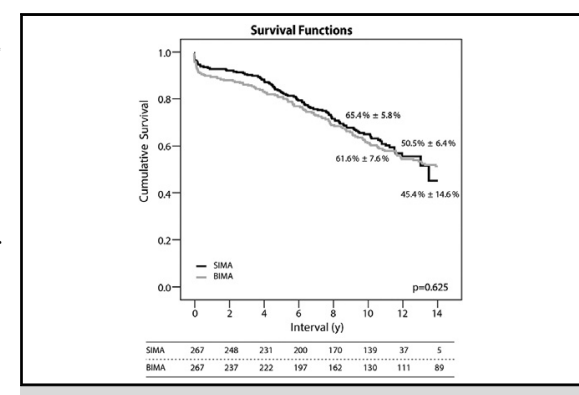

Survival of the groups treated with BIMA grafting and with single IMA + RA grafting, after propensity-score matching. Long-term survival of patients undergoing composite T-grafting with single, left, IMA and RA is not inferior to that with BIMA grafting. Values in rows below graph indicate numbers of patients receiving each treatment at corresponding number of years.

Central Message

Composite T-grafting with a single, left internal mammary artery + radial artery, is as good as bilateral mammary grafting; a radial artery $\mathrm{T}$-graft is recommended.

Perspective

Bilateral internal mammary grafting is associated with improved survival. However, surgeons are reluctant to use this technique, owing to increased risk of sternal infection. This study has shown that the long-term outcomes of revascularization with a composite T-graft incorporating the RA attached end-to-side to the left IMA are as good as those with BIMA grafting. This technique provides arterial revascularization with lower risk of sternal infection.

See Editorial Commentary page 1320.

\footnotetext{
From the ${ }^{\mathrm{a}}$ Department of Cardiothoracic Surgery, Tel Aviv Sourasky Medical Center; ${ }^{\mathrm{b}}$ Faculty of Medicine, Tel Aviv University; and ${ }^{\mathrm{c}}$ Department of Cardiothoracic Surgery, Rabin Medical Center, Petah Tikva, Tel Aviv, Israel.

Nahum Nesher and Benjamin Medalion contributed equally to this work.

Received for publication Jan 27, 2015; revisions received Nov 20, 2015; accepted for publication Dec 7, 2015; available ahead of print Jan 13, 2016.

Address for reprints: Rephael Mohr, MD, Department of Cardiothoracic Surgery, Tel Aviv Sourasky Medical Center, 6 Weizman St, Tel Aviv 64239, Israel (E-mail: pevnid@gmail.com).

$0022-5223 / \$ 36.00$

Copyright (C) 2016 by The American Association for Thoracic Surgery

http://dx.doi.org/10.1016/j.jtcvs.2015.12.005
}

The use of internal mammary artery (IMA) grafting in patients who have multivessel coronary disease is associated with improved long-term survival. ${ }^{1}$ Further,

Scanning this $\mathrm{QR}$ code will take you to the article title page.

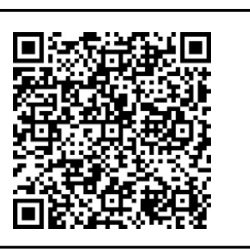




$$
\begin{aligned}
& \text { Abbreviations and Acronyms } \\
& \begin{aligned}
\text { BIMA } & =\text { bilateral internal mammary artery } \\
\text { CI } & =\text { confidence interval } \\
\text { COPD } & =\text { chronic obstructive pulmonary disease } \\
\text { IMA } & =\text { internal mammary artery } \\
\text { MI } & =\text { myocardial infarction } \\
\text { OR } & =\text { odds ratio } \\
\text { RA } & =\text { radial artery }
\end{aligned}
\end{aligned}
$$

survival benefit may be achieved with the use of 2 IMAs, ie, bilateral IMA (BIMA) for revascularization of the left coronary system. ${ }^{2}$ Therefore, various strategies for left-sided (left anterior descending and circumflex) revascularization were developed. One popular technique that enables complete arterial revascularization of the left system is the composite T-graft. $^{3}$ Mid- and long-term outcomes of patients undergoing BIMA grafting using composite T-grafts are similar to those using only in-situ grafts. ${ }^{4,5}$

Despite the better long-term survival, BIMA grafting is not being used routinely by many surgeons, owing to the reported increased risk of sternal wound complications. ${ }^{6}$ However, the good clinical outcomes of patients undergoing BIMA grafting, along with the early, or earlier, failure of saphenous vein grafts, has led to the introduction of other arterial conduits into clinical practice, in the belief that their long-term patency will be better than that of saphenous vein grafts. One of the free arterial conduits thus introduced was the radial artery (RA). In our practice, we followed suggestions made by Calafiore and colleagues ${ }^{5}$ and connected the free RA end to the side of the left IMA, thus constructing a composite T-graft with this conduit.

The purpose of this report is to compare long-term outcomes of composite T-grafting using 2 IMAs with that using a single IMA and the RA. To control for bias in preoperative patient selection, we compared long-term results after propensity-score matching.

\section{METHODS}

This retrospective review of medical records and telephone questionnaires obtaining follow-up was approved by the Institutional Review Board of the Tel Aviv Medical Center. Between 1996 and 2010, a total of 3165 consecutive patients with multivessel coronary artery disease underwent left-sided arterial revascularization at the center. They constituted $74.9 \%$ of primary coronary artery bypass grafting procedures for multivessel disease that were performed in our institution during this time period. The composite T-graft technique ${ }^{7,8}$ was employed in 1718 of them. In 1329 patients, one IMA (in most cases, the right) was attached end-to-side to the other IMA. In the remaining 389 patients, the RA was connected end-to-side to the left IMA.

The BIMA grafting method was the dominant revascularization procedure performed in our institution throughout the study period for patients who had multivessel disease (4247 patients). In all, 3165

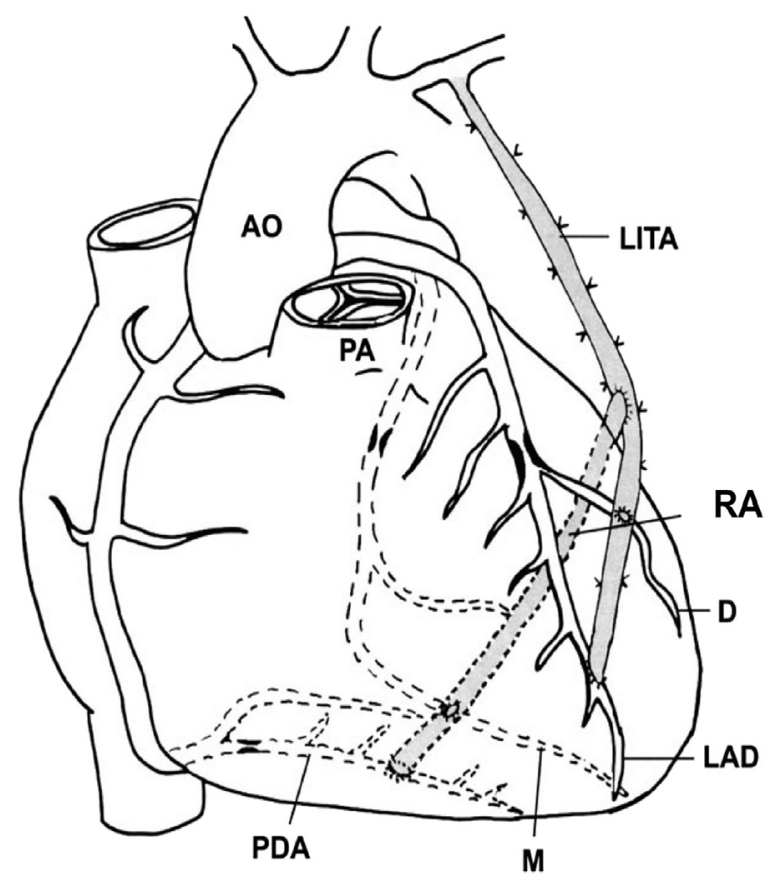

FIGURE 1. Composite T-graft with radial artery attached end-to-side to the left internal mammary artery. $A O$, Aorta; LITA, left interior mammary artery; $P A$, pulmonary artery; $R A$, radial artery; $D$, descending; $P D A$, pulmonary descending artery; $M$, main; $L A D$, left anterior descending.

(74.9\%) underwent left-sided arterial revascularization (2776 BIMA and 389 single IMA + RA procedures); the remaining 1082 underwent single IMA + saphenous vein grafting.

During the study period, selection criteria for BIMA versus single IMA and RA were made mainly according to surgeon preference. The overall tendency was to not use BIMA in patients at increased risk for sternal wound complications (elderly, those who had COPD, or women who had diabetes and/or obesity). ${ }^{9}$ In addition, a composite T-graft with RA was used $^{10,11}$ only when target coronary vessel stenosis was $>80 \%$. Surgeries for $363(21.2 \%)$ of the patients were performed without extracorporeal circulation. $^{7,8}$

All IMAs were harvested as skeletonized vessels. ${ }^{7}$ Revascularization of the right system was performed with saphenous vein grafts, the right gastroepiploic artery, or the RA (Figure 1). From the second postoperative day, those who received the latter 2 were treated with oral calcium channel blockers (diltiazem), at 90 to $180 \mathrm{mg}$.

\section{Definitions and Data Collection}

Patient data were analyzed according to euroSCORE (European System for Cardiac Operative Risk Evaluation) clinical data standards. ${ }^{12}$ Diabetic patients included those treated with insulin or oral hypoglycemic agents. A perioperative myocardial infarction (MI) was defined as the postoperative appearance of new Q waves or an ST-segment elevation of $>2 \mathrm{~mm}$ on an electrocardiogram, accompanied by a creatine phosphokinasemyocardial band $>50 \mathrm{mU} / \mathrm{mL}$, with or without a regional wall motion abnormality. ${ }^{13}$

A cerebrovascular accident was defined as a new permanent neurologic deficit and computed tomographic evidence of cerebral infarction. Deep sternal infection in this setting was defined as the presence of deep infection, in combination with late dehiscence requiring sternectomy. An emergency operation was one performed within 24 hours of coronary angiography. $^{12}$ 


\section{Statistical Analysis}

All data were summarized and displayed as mean ( \pm standard deviation), or median (25\%-75\%) for continuous variables, and as number $(\%)$ of patients in each group for categoric variables. Categoric variables were compared using $\chi^{2}$ analysis or the Fisher exact test, as appropriate. Continuous variables were compared using the independent-sample $t$ test or the Mann-Whitney $U$ test.

Propensity score was used to account for differences between groups in preoperative characteristics. The probability (propensity score) that a patient would receive an RA graft or undergo BIMA grafting, according to preoperative variables, was determined by using a logistic regression model. ${ }^{14}$ The preoperative patient characteristics used for propensityscore analysis were: age, gender, diabetes, peripheral vascular disease, emergency operation, critical preoperative state, old MI, acute MI, repeat operation, renal insufficiency, congestive heart failure, chronic obstructive pulmonary disease, unstable angina, left main disease, number of diseased vessels, and left ventricular ejection fraction.

Multivariate analysis of short-term outcome (operative mortality, sternal wound complications, perioperative MIs, and strokes) was performed using binary logistic regression analysis. Adjusted odds ratio (OR) and $95 \%$ confidence interval (CI) were reported. Follow-up was obtained using the Israeli National Registry database. The log-rank test and Kaplan-Meier curves were used to compare survival between groups.

Multivariate Cox regression was used for long-term outcome analysis. Adjusted hazard ratio and 95\% confidence interval (CI) were reported. The type of conduit used (BIMA or RA) and the propensity score were forced into the multivariate models. We used a forward, stepwise selection method for predictors to be included in the multivariate analysis. These included the following preoperative and operative data: age; gender; diabetes; peripheral vascular disease; emergency operation; critical preoperative state; old MI; acute MI; repeat operation; renal insufficiency; congestive heart failure; chronic obstructive pulmonary disease; unstable angina; left main disease; number of diseased vessels; left ventricular ejection fraction; number of grafts constructed; use of operative techniques, such as off-pump coronary artery bypass and sequential grafting; and use of other conduits, such as saphenous vein grafting or right gastroepiploic artery.

A propensity-score matching method was used to generate a subcohort for further evaluation of early and long-term outcomes. Patients were matched using the propensity score, with a $5 \%$ difference as a matching threshold value. Multivariate conditional logistic regressions were performed to evaluate the association between the type of conduit used (group) and short-term outcomes.

Kaplan-Meier survival was used to describe the survival in the matched groups. Univariate and multivariate Cox regressions were used to compare long-term outcome between the matched groups. The Cox regression was stratified by the pair variable. Variable selection in the multivariate analyses in the matched subcohort was performed as for the whole cohort. Statistical analysis was performed with SPSS, version 22 (SPSS, Inc, Chicago, Ill) statistical software.

\section{RESULTS}

Preoperative patient characteristics were significantly different between groups before matching (Table 1). Patients treated with a single IMA and RA were older; they were more likely to have diabetes, COPD, chronic renal failure, and peripheral vascular disease; be women; and have undergone repeat and emergency operations. On the other hand, acute MI, recent and old MI, left main disease, and congestive heart failure were more prevalent in the group treated with BIMA grafting. The euroSCORE of the group treated with RA grafting was significantly
TABLE 1. Patient characteristics before matching

\begin{tabular}{|c|c|c|c|}
\hline Variable & $\begin{array}{c}\text { Bilateral IMA } \\
\mathbf{n}=\mathbf{1 3 2 9}\end{array}$ & $\begin{array}{c}\text { Single IMA } \\
\mathbf{n}=\mathbf{3 8 9}\end{array}$ & $P$ value \\
\hline \multicolumn{4}{|l|}{ Age (y) } \\
\hline$\leq 65$ & $601(45.8)$ & $132(33.9)$ & $<.001$ \\
\hline $66-75$ & $496(37.3)$ & 157 (40.4) & \\
\hline$>75$ & $232(17.5)$ & $100(25.7)$ & \\
\hline Female & $290(21.8)$ & 139 (35.7) & $<.001$ \\
\hline NIDDM & $465(35)$ & 193 (49.6) & .003 \\
\hline IDDM & $44(3.3)$ & 45 (11.6) & $<.001$ \\
\hline $\mathrm{DM}+\mathrm{EOD}$ & $84(6.3)$ & 88 (22.6) & $<.001$ \\
\hline PVD & 298 (22.4) & 119 (30.6) & .001 \\
\hline COPD & $67(5.0)$ & 58 (14.9) & $<.001$ \\
\hline $\mathrm{CHF}$ & $350(26.3)$ & $81(20.8)$ & .015 \\
\hline $\mathrm{CRF}(\mathrm{Cr}>1.8)$ & $105(7.9)$ & 45 (11.6) & .018 \\
\hline Recent MI & 450 (33.9) & $108(27.8)$ & .013 \\
\hline Old MI & $528(39.7)$ & $134(34.4)$ & .034 \\
\hline Acute MI (7 d) & $282(21.2)$ & $59(15.2)$ & .005 \\
\hline $\mathrm{EF} \leq 30$ & $107(8.1)$ & $24(6.2)$ & .130 \\
\hline Preop. IABP & $81(6.1)$ & $26(6.7)$ & .374 \\
\hline Emergency & $199(15.0)$ & $75(19.3)$ & .026 \\
\hline Repeat operation & $30(2.3)$ & $22(5.7)$ & .001 \\
\hline Unstable angina & 767 (57.7) & $240(61.7)$ & .089 \\
\hline Status post PCI & $195(15.0)$ & $64(16.5)$ & .265 \\
\hline LM & $388(29.2)$ & 89 (22.9) & .008 \\
\hline $3 \mathrm{VD}$ & $1031(77.3)$ & $302(77.6)$ & .506 \\
\hline $\begin{array}{c}\text { euroSCORE, mean } \pm \\
\text { standard deviation }\end{array}$ & $5.80 \pm 3.24$ & $7.44 \pm 4.12$ & $<.001$ \\
\hline 1996-2000* & $970(73)$ & $27(6.9)$ & $<.001$ \\
\hline
\end{tabular}

Values are $\mathrm{n}(\%)$, unless otherwise indicated. IMA, Internal mammary artery $N I D D M$, non-insulin dependent diabetes mellitus; IDDM, insulin-dependent diabetes mellitus; $D M+E O D$, diabetes mellitus + end organ damage; $P V D$, peripheral vascular disease; $C O P D$, chronic obstructive pulmonary disease; $C H F$, congestive heart failure; $C R F$, chronic renal failure; $C r$, creatine; $M I$, myocardial infarction; $E F$, ejection fraction; Preop., preoperative; IABP, intra-aortic balloon pump; $P C I$, percutaneous intervention; $L M$, left main; $3 V D$, triple-vessel disease; euroSCORE, European System for Cardiac Operative Risk Evaluation. *Operative period.

higher than that of the group treated with BIMA grafting (Table 1). The extent of coronary artery involvement did not differ significantly between groups (prevalence of 3 -vessel disease was $77.6 \%$ in both groups).

Operative mortality in the groups treated with BIMA and RA grafting, respectively, was $39(2.9 \%)$ and $15(3.9 \%)$ patients, $P=.225$. Occurrence was similar in the 2 groups, respectively, of sternal infection at $27(2.0 \%)$ versus 11 $(2.8 \%), P=.225$; stroke $45(3.4 \%)$ versus $7(1.8 \%)$, $P=.069$; and perioperative MI $15(1.1 \%)$ versus 8 $(2.1 \%), P=.128$.

After forcing propensity score and operative period into the logistic regression model, independent predictors of increased operative mortality were: chronic renal failure (OR 2.7, $P=.007$ ); ejection fraction $\leq 30 \%$ (OR 2.4, $P=.017)$; critical preoperative state $^{12}$ (OR 4.7, $P<.001$ ); neurologic dysfunction (OR 2.7, $P=.038$ ); and left main disease (OR 2.5, $P=.002$ ). The type of conduit employed was not found to be a significant 


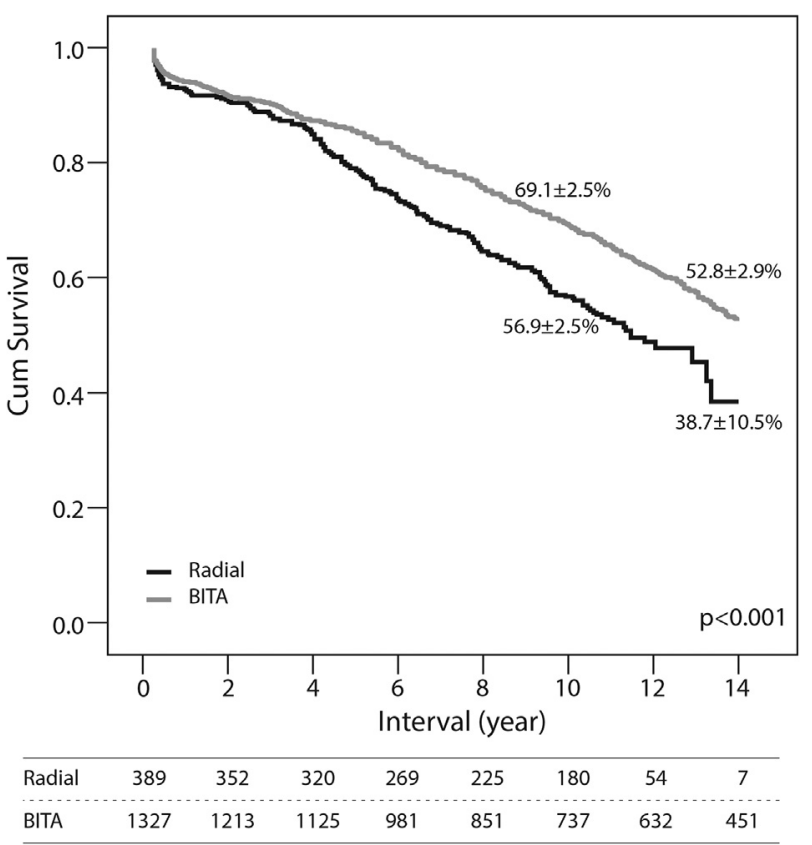

FIGURE 2. Kaplan-Meier survival curves of patients in the group treated with BIMA grafting and those in the group treated with single IMA + RA grafting, before matching. Values in rows below graph indicate numbers of patients receiving each treatment at corresponding number of years. BIMA, Bilateral internal mammary artery.

predictor for operative mortality (OR 7.6, $P=.718$ ); postoperative stroke (OR 1.2, $P=.739$ ); or sternal wound infection (OR $0.7, P=.538$ ). Independent predictors of sternal infection were: non-insulin dependent diabetes mellitus (OR 2.8, $P=.006$ ); insulin-dependent diabetes mellitus (OR 4.4, $P=.018$ ); and COPD (OR 6.1 $P<.001)$. Independent predictors of stroke were: noninsulin dependent diabetes mellitus (OR 3.3, $P<.001$ ); preoperative cerebrovascular disease (OR 7.1, $P<.001$ ); and left main disease (OR 2.5, $P=.003$ ).

Follow-up was $97 \%$ complete. The median follow-up was 14.19 (95\% CI 13.43-14.95) years. The 10-year survival (Kaplan-Meier) of the group receiving RA grafting was significantly lower than that of the group receiving BIMA grafting $(56.9 \%+2.6 \%$ vs $69.1 \%+1.3 \%$, respectively, $P<.001$, log-rank test; Figure 2). However, assignment to the latter group was not associated with better propensity-adjusted survival (hazard ratio $1.281,95 \%$ CI $0.997-1.647, P=.053$, compared with the group treated with single IMA + RA grafting [Cox model]). To compare outcomes between groups, propensity-score matching was performed, and 268 pairs of well-matched patients from the 2 groups were created (Table 2; Figure 3).

Routine use of off-pump coronary artery bypass and arterial revascularization with single IMA + RA were introduced to our center in 1999. The recency of this date
TABLE 2. Patient characteristics after matching

\begin{tabular}{|c|c|c|c|}
\hline Variable & $\begin{array}{c}\text { Bilateral IMA } \\
\quad \mathbf{n}=\mathbf{2 6 8}\end{array}$ & $\begin{array}{c}\text { Single IMA } \\
\mathbf{n}=\mathbf{2 6 8}\end{array}$ & $P$ value \\
\hline \multicolumn{4}{|l|}{ Age (y) } \\
\hline$\leq 65$ & $111(41.4)$ & $104(38.8)$ & .432 \\
\hline $66-75$ & $109(40.7)$ & $104(38.8)$ & \\
\hline$\geq 76$ & 48 (17.9) & $60(22.4)$ & \\
\hline Female & $83(31)$ & $82(30.6)$ & .500 \\
\hline NIDDM & $127(47.4)$ & $124(46.3)$ & .431 \\
\hline IDDM & $18(6.7)$ & $16(6)$ & .430 \\
\hline $\mathrm{DM}+\mathrm{EOD}$ & $29(10.8)$ & $27(10.1)$ & .444 \\
\hline PVD & $60(22.4)$ & $55(20.5)$ & .337 \\
\hline COPD & $33(12.3)$ & $22(8.2)$ & .077 \\
\hline $\mathrm{CHF}$ & $51(19)$ & $50(18.7)$ & .500 \\
\hline $\mathrm{CRF}(\mathrm{Cr}>1.8)$ & $22(8.2)$ & $22(8.2)$ & .562 \\
\hline Recent MI & $68(25.4)$ & $66(24.6)$ & .468 \\
\hline Old MI & $95(35.4)$ & $90(33.6)$ & .358 \\
\hline Acute MI (7 d) & 37 (13.8) & $40(14.9)$ & .403 \\
\hline $\mathrm{EF} \leq 30$ & $10(3.7)$ & $11(4.1)$ & .500 \\
\hline Preop. IABP & $18(6.7)$ & $15(5.6)$ & .360 \\
\hline Emergency & $43(16.0)$ & $45(16.8)$ & .026 \\
\hline Repeat op. & $7(2.6)$ & $14(5.2)$ & .090 \\
\hline Unstable angina & 149 (55.6) & $151(56.3)$ & .465 \\
\hline Status post PCI & 31 (11.7) & $49(18.3)$ & .023 \\
\hline LM & 64 (23.9) & $59(22)$ & .345 \\
\hline $3 \mathrm{VD}$ & $219(81.7)$ & $211(78.7)$ & .842 \\
\hline $\begin{array}{l}\text { euroSCORE, mean } \pm \text { standard } \\
\text { deviation }\end{array}$ & $6.05 \pm 3.31$ & $5.90 \pm 3.17$ & .604 \\
\hline $1996-2000^{*}$ & $199(74.3)$ & $15(5.6)$ & $<.001$ \\
\hline
\end{tabular}

Values are $\mathrm{n}(\%)$, unless otherwise indicated. IMA, Internal mammary artery; $N I D D M$, non-insulin dependent diabetes mellitus; IDDM, insulin-dependent diabetes mellitus; $D M+E O D$, diabetes mellitus + end organ damage; $P V D$, peripheral vascular disease; $C O P D$, chronic obstructive pulmonary disease; $C H F$, congestive heart failure; $C R F$, chronic renal failure; $C r$, creatine; $M I$, myocardial infarction; $E F$, ejection fraction; Preop., preoperative; IABP, intra-aortic balloon pump; op., operation; $P C I$, percutaneous intervention; $L M$, left main; $3 V D$, triple-vessel disease; euroSCORE, European System for Cardiac Operative Risk Evaluation. *Operative period.

can explain differences in surgical techniques between the 2 matched groups (Table 3). The RA is longer than the right IMA, enabling more-sequential grafting and more-frequent revascularization of the right coronary artery system with its distal end. These factors can explain the less-frequent use of saphenous vein grafting and right gastroepiploic arteries in the group treated with left IMA + RA grafting (Table 3).

Early mortality ( 30 days) of the 2 matched groups was not significantly different $(3.7 \%$ and $3.4 \%, P=.5$, with BIMA vs single IMA + RA grafting, respectively). In addition, the groups had a similar prevalence of early postoperative, deep sternal infection $(2.6 \%$ vs $4.1 \%$, $P=.22)$, and perioperative MI $(1.9 \%$ vs $3.4 \%$, $P=.209)$. The rate of postoperative stroke was higher with BIMA grafting $(5.6 \%$ vs $1.9 \%, P=.019)$; however, the type of composite graft performed (BIMA or 


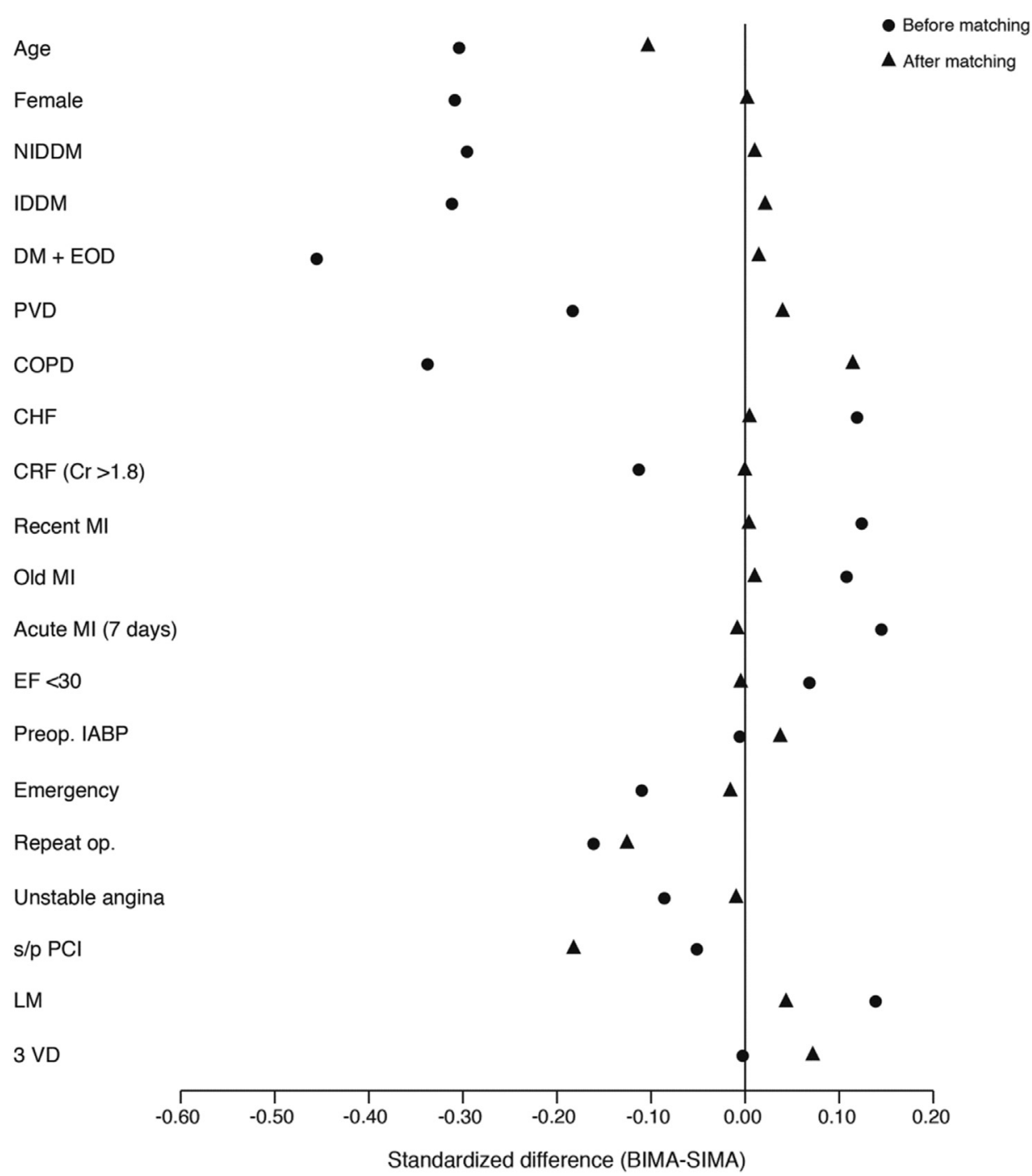

FIGURE 3. Standardized differences plot (BIMA vs SIMA + RA). NIDDM, Non-insulin-dependent diabetes mellitus; IDDM, insulin-dependent diabetes mellitus; $D M$, diabetes mellitus; $E O D$, end organ damage; $P V D$, peripheral vascular disease; $C O P D$, chronic obstructive pulmonary disease; $C H F$, congestive heart failure; $C R F$, chronic renal failure; $C r$, creatine; $M I$, myocardial infarction; $E F$, ejection fraction; Preop., preoperative; $I A B P$, intra-aortic balloon pump; op., operation; s/p PCI, status post percutaneous coronary intervention; $L M$, left main; 3 VD, 3-vessel disease; BIMA, bilateral internal mammary artery; SIMA, single internal mammary artery.

IMA + RA) was not found to be a significant predictor of stroke in multivariable analysis (hazard ratio 1.7, $P=.262$ ).

Kaplan-Meier 10-year survival of the 2 matched groups was not significantly different $(64.9 \% \pm 3.0 \%$ and $61.6 \% \pm 3.1 \%$ for the single IMA + RA, and BIMA, grafts, respectively, $P=.652$, log-rank test; Figure 4 ), and the use of BIMA or single IMA + RA did not emerge as an independent predictor for late mortality (hazard ratio $1.231,95 \%$ CI $0.667-2.273, P=.507$ ) (Cox model).

Independent predictors of decreased survival were age and chronic renal failure. The operative period (1996-2000 vs 2001-2010), which was forced into the model, did not emerge as a significant predictor of decreased survival. Despite the differences between groups in surgical parameters (such as off-pump coronary artery bypass, use of right gastroepiploic artery, and saphenous vein grafts [Table 3]), the only surgical variable that had significant influence on long-term survival was the number of grafts performed (Table 4). To further validate our results, we performed stratified propensity analysis according to quintiles, which failed to demonstrate superiority of the BIMA compared with the RA as a composite T-graft.

\section{DISCUSSION}

This retrospective report evaluates long-term clinical outcome of coronary artery bypass grafting in patients 
TABLE 3. Surgical data

\begin{tabular}{lccc}
\hline \multicolumn{1}{c}{ Variable } & $\begin{array}{c}\text { Bilateral IMA } \\
\mathbf{n = 2 6 8}\end{array}$ & $\begin{array}{c}\text { Single IMA } \\
\mathbf{n}=\mathbf{2 6 8}\end{array}$ & $\boldsymbol{P}$ value \\
\hline OPCAB & $43(16)$ & $105(42.2)$ & .000 \\
Sequential grafting & $163(61.3)$ & $186(69.4)$ & .030 \\
Use of SVG & $70(26.1)$ & $30(11.2)$ & .001 \\
Use of right GEA & $30(11.2)$ & $2(0.7)$ & .000 \\
No. of grafts $>3$ & $213(79.5)$ & $194(72.4)$ & .034 \\
\hline
\end{tabular}

$I M A$, Internal mammary artery; $O P C A B$, off-pump coronary artery bypass; $S V G$, saphenous vein graft; $G E A$, gastroepiploic artery.

who have multivessel disease who underwent arterial revascularization using the composite $\mathrm{T}$-graft technique. A series of patients in whom RA was attached end-to-side to the left IMA is compared with a cohort of patients who underwent BIMA grafting. Extensive arterial grafting with BIMA had been used in the past preferentially in a selected group of young male, non-obese, nondiabetic patients in several studies. ${ }^{2,3,6}$ Patients were preselected for BIMA grafting according to their life expectancy, and only a few patients who had comorbidities, such as diabetes, recent MI, and peripheral vascular disease, and patients aged $>70$ years, were offered the option of BIMA grafting.

Unlike those trials, patients in the current study were not preselected for BIMA grafting according to their comorbidities and life expectancy. Routine left-sided arterial (left

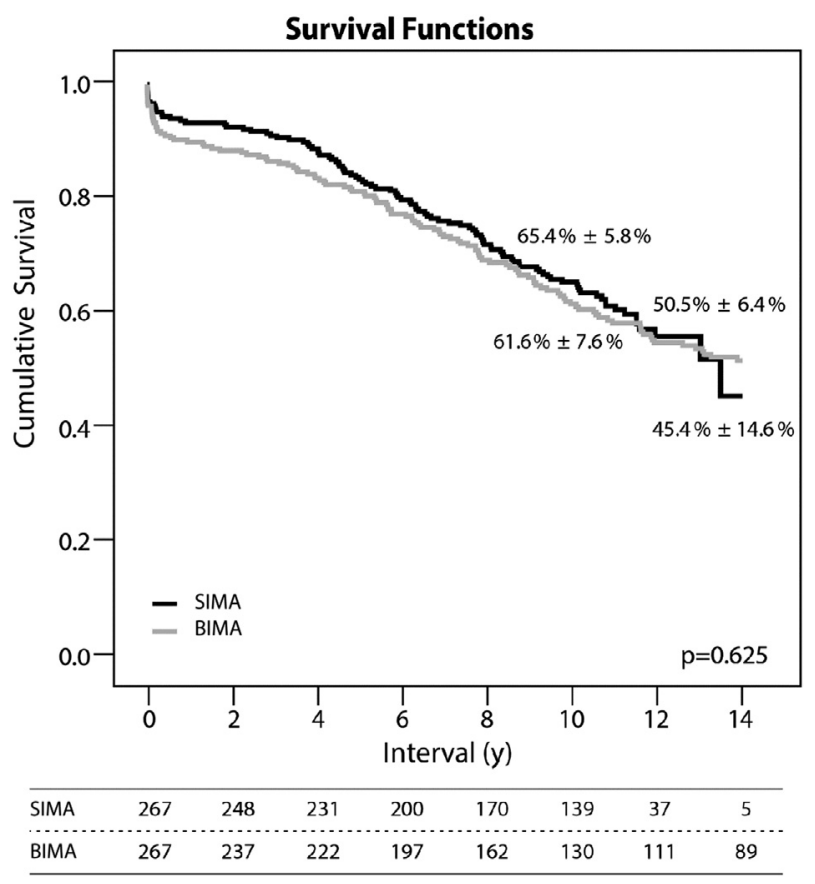

FIGURE 4. Survival of the groups treated with BIMA grafting and single IMA + RA grafting, after propensity-score matching. Values in rows below graph indicate numbers of patients receiving each treatment at corresponding number of years. SIMA, Single internal mammary artery; $B I M A$, bilateral internal mammary artery.
TABLE 4. Independent predictors for overall (early + late) mortality

\begin{tabular}{lcc}
\hline \multicolumn{1}{c}{ Variable } & Hazard ratio $(\mathbf{9 5} \% \mathbf{C I})$ & $\boldsymbol{P}$ value \\
\hline Age & $1.051(1.019-1.084)$ & .002 \\
CRF & $4.15(1.65-10.41)$ & .003 \\
Recent MI & $2.35(1.19-4.65)$ & .013 \\
Bypass, $\geq 3$ & $0.37(0.18-0.74)$ & .005 \\
OPCAB & $1.76(1.90-3.46)$ & .099 \\
Op. period (1996-2000) & $1.65(0.81-3.39)$ & .172 \\
Conduit - RA & $1.22(0.67-2.23)$ & .514 \\
\hline
\end{tabular}

Other variables in the model are: gender $(P=.116)$; diabetes $(P=.233)$; COPD $(P=.245)$; CHF $(P=.277)$; old MI $(P=.303)$; unstable angina $(P=.135)$; $\mathrm{EF}<30 \%(P=.935)$; emergency $(P=.441) ; P V D(P=.248)$; sequential grafting $(P=.352)$; and $S V G(P=.884) . C I$, Confidence interval; $C R F$, chronic renal failure; $M I$, myocardial infarction; $O P C A B$, off-pump coronary artery bypass; $o p$., operative; $R A$, radial artery.

anterior descending and circumflex system) revascularization was the preferred method of revascularization in our center during the study period. ${ }^{4,7,8}$ Thus, most (3165 $[74.9 \%])$ patients who underwent the primary coronary artery bypass grafting procedures for multivessel disease performed in our institution during the study period, had skeletonized BIMA grafting or single IMA incorporating RA grafting. The composite T-graft technique ${ }^{7,8}$ was employed in 1718 patients. In 1329 of them, one IMA (in most cases, the right) was attached end-to-side to the other IMA (in most cases, the left). In the remaining 389 patients, the RA was connected end-to-side to the left IMA.

The thick, muscular RA media predispose this conduit to spasm, in response to tactile stimuli and various pharmacologic agents, such as potassium chloride and norepinephrine. ${ }^{15}$ To prevent RA spasm, we followed during the study period the technical recommendations made by Rehman, Yi, and Taggart. ${ }^{15}$ The RA was harvested from the nondominant hand as a pedicle, using a harmonic scalpel. We used topical application of alpha-blockers or calcium channel blockers after partial skeletonization of the artery, as a means to prevent intraoperative spasm.

The surgeons made an effort to select for BIMA grafting those patients with reduced risk of deep sternal wound complications.The high-risk group of patients (the elderly, those with diabetes, and obese women $)^{9}$ were commonly referred during the study period to the single IMA + RA grafting group or treated with IMA saphenous vein grafting. herefore, patients in the group treated with single IMA + RA were older, more often female, and more likely to have diabetes, COPD, chronic renal failure, and peripheral vascular disease, and to have had a repeat or emergency operation. The euroScore of the RA-treated group was significantly higher than that of the BIMAtreated group $(7.44 \pm 4.12$ vs $5.80 \pm 3.24, P<.001)$ (Table 1).

Propensity matching was used to account for differences between groups in preoperative demographic characteristics. The risk profile of the matched groups thus created is 
largely affected by the higher risk of the RA-treated group. This factor can explain the high occurrences of comorbidities and emergency operations, and the relatively unfavorable long-term outcomes of patients in our study, compared with outcomes in other BIMA series. ${ }^{2,3,5,16,17}$

Another important selection criterion for use of RA grafting during the study period was the degree of target coronary artery stenosis. Surgeons refrained from using the RA to bypass vessels that showed less-than-severe stenosis $(80 \%-90 \%)$ because of the increased graft occlusion and string sign that have demonstrated in RAs used to bypass coronary vessels that have a lesser degree of stenosis. ${ }^{18,19}$

The main finding in this report is that early and long-term outcomes of the 2 composite groups were similar. Operative mortality and occurrences of sternal infection, stroke, and perioperative MI in the 2 groups before matching were similar. Moreover, the type of conduit employed was not found to be a significant predictor for operative mortality, sternal wound infection, perioperative MI, or stroke in multivariable analyses performed after forcing propensity score and operative period into the multivariable models.

Our study suggests that after a relatively long follow-up (mean 14.2 years), survival of patients who were treated with single IMA + RA grafting, attached end-to-side to the IMA, as a composite T-graft, is not inferior to that found with BIMA treatment. Meta-analysis of studies comparing RA and saphenous vein grafts suggests that early patency rate ( $\leq 1$ year) of the RA is similar to that of saphenous vein grafting. Medium-term (1-5 years) patency of saphenous vein grafting deteriorates significantly, and long-term patency ( $\geq 5$ years) of the RA is better. ${ }^{20-22}$

Ours is not an angiographic study, and patency rate was not evaluated. However, the findings support the notion that arterial revascularization with a single IMA, and the RA as a second arterial conduit, is better than myocardial revascularization with a single IMA and saphenous vein grafting. ${ }^{22}$ Our study is strongly supported by 2 recently published, large, propensity-score-matched studies with relatively long follow-up, the findings of which cast doubt on the notion of superiority of the right IMA compared with the RA as an arterial graft to bypass the circumflex coronary artery. ${ }^{23,24}$ In the study by Tranbaugh and colleagues, ${ }^{23}$ spanning up to 18 years, Kaplan-Meier 10-year survival, and Cox-adjusted survival, were used to compare survival of BIMA-treated and RA-treated patients who underwent left-sided arterial revascularization. Propensity matching was performed on 2488 patients receiving left IMA grafting, from 2 centers, resulting in 528 pairs who received either an RA graft at one center or a free right IMA attached proximally to the aorta at the other center.

The 2 matched groups showed similar 10-year survival $(85 \%$ vs $80 \%)$ and similar Cox-adjusted survival. In addition, they showed similar patency, of $84 \%$ and $87 \%$ for the RA and right IMA, respectively. More major adverse events occurred in the right IMA-treated group, especially in obese patients and patients who had diabetes and COPD; hence, their results favored the RA graft, compared with the right IMA graft. In a study by Navia and colleagues, ${ }^{24} 1447$ off-pump coronary artery bypass BIMA-treated patients were compared with 253 RA-treated patients. Composite T-grafting was employed in most of the patients in both groups. Propensity-score matching was used to compare the groups, generating 149 pairs of well matched groups.

Postoperatively, fewer reinterventions and readmissions occurred in the BIMA-treated group; however, as in our study, long-term survival of the 2 matched groups was similar. Our results stand in contrast to results of another recently published propensity score-matched study by Ruttmann and colleagues. ${ }^{17}$ That study showed that the right IMA is better than the RA as a second arterial conduit. The difference in long-term results between that study and our study likely stems from differences in patient selection: BIMA grafting in our study was the preferred revascularization strategy for patients who had multivessel disease. Thus, composite T-grafts with BIMA were performed in most patients before matching $(77 \%)$. In the other study, ${ }^{17}$ BIMA grafting constituted only $27.7 \%$ of the patients studied, reflecting the more selective use of BIMA for young nonemergent patients who had fewer comorbidities.

The good, early and midterm outcomes of the BIMA-treated group in this report ${ }^{17}$ are similar to the quality of outcomes achieved in older BIMA studies, in which higher-risk post-MI and emergency patients were preselected for operations incorporating single IMA and saphenous vein grafting. The propensity-matched BIMA-treated patients in the study by Ruttmann and colleagues ${ }^{17}$ were practically identical to the BIMA-treated patients before matching. This selective use of BIMA treatment and the shorter follow-up period are the main explanations for the better survival in their study, compared with our study, in which the population was significantly higher-risk patients. The euroSCORE of matched patients in our study was 6, compared with 2.3 in their study. Aside from the selective use of BIMA treatment in that study, the improved outcome with BIMA treatment and diminished results with RA treatment may be the result of using in-situ, rather than free IMA, grafts, as opposed to free RA grafts implanted on the aorta, as in this report.

The improved clinical outcome of RA patients in our study might result from better patency of the RA when it is connected proximally to the left IMA. This possibility is not supported by angiographic data; however, when the RA is connected proximally to the left IMA, it is exposed 
to the nitric oxide-rich environment of the IMA and may therefore perform better than when it is grafted proximally to the ascending aorta. ${ }^{25}$ The improved results of the patients in the RA + IMA group, and masking of BIMA-grafting benefits by earlier mortality from noncardiac causes, reduce the contribution of the type of conduit used, making results similar to the Cox-adjusted survival model in our study and those by Navia and colleagues ${ }^{22}$ and Tranbaugh and colleagues. ${ }^{23,24}$ Thus, the contribution of competing preoperative comorbidities and advanced age to adjusted mortality likely played a large role. These results call into question the notion that using the BIMA treatment rather than the RA treatment provides advantages in these high-risk patients.

\section{Limitations}

This is a single-center observational retrospective study and carries the associated limitations. Supplemental angiographic data strongly support the evidence from clinical observation. An additional limitation is possible selection bias in the criteria used to select the second arterial conduit. These include: (1) variables that were not assessed (eg, coronary pathology, diffuse coronary disease, atrial fibrillation, history of malignancy, and medical therapy after surgery) and (2) possible selection of some patients for the RA group based on surgeon anticipation that this longer graft can reach the right coronary artery system more easily. None of these covariates could be accounted for in the propensity-matching procedure.

Another limitation is that retrieval of retrospectively complete follow-up data was not possible for all major adverse events. Thus, endpoints such as late MI, cardiac mortality, and reinterventions that were not collected prospectively were not complete, and their occurrences could not be compared between groups; therefore, major adverse events was not included as a variable in the study. Given the sample size of the matched groups, and the reported better patency rate of the right IMA, a much more likely possibility is that a comparison of event-free survival would have revealed differences between groups.

\section{CONCLUSIONS}

Long-term survival of patients undergoing composite T-grafting with single left IMA + RA is not inferior to that of patients treated with BIMA grafting. Earlier mortality from noncardiac causes reduces the influence of the type of conduit, and increases the influence of competing preoperative comorbidities, on Cox-adjusted survival. Selective use of BIMA grafting in lower-risk patients might unmask the benefits of this procedure. Results of this large observational study do not support routine use of BIMA grafting. The use of an RA T-graft is recommended in high-risk patients.

\section{Conflict of Interest Statement}

Dr Ben-Gal reports consulting fees from and equity ownership in Vascular Graft Solutions. All other authors have nothing to disclose with regard to commercial support.

\section{References}

1. Loop FD, Lytle BW, Cosgrove DM, Steward RW, Goormastic M, Williams GW, et al. Influence of the internal mammary artery graft on 10-year survival and other cardiac events. N Engl J Med. 1986;314:1-6.

2. Lytle BW, Blackstone EH, Loop FD, Houghtling PL, Arnold JH, Akhrass R, et al. Two internal thoracic arteries are better than one. J Thorac Cardiovasc Surg. 1999; 117:855-72.

3. Tector AJ, Amundsen S, Schmahl TM, Kress DC, Peter M. Total revascularization with T-grafts. Ann Thorac Surg. 1994;57:33-8.

4. Lev-Ran O, Paz Y, Pevni D, Kramer A, Shapira I, Locker C, et al. Bilateral internal thoracic artery grafting: midterm results of composite versus in situ crossover graft. Ann Thorac Surg. 2002;74:704-10.

5. Calafiore AM, Contini M, Vitolla G, Di Mauro M, Mazzel V, Teodori G, et al Bilateral internal thoracic artery grafting: long-term clinical and angiographic results of in situ versus Y grafts. J Thorac Cardiovasc Surg. 2000;120:990-8.

6. Taggart DP, D'Amico R, Altman DG. Effect of arterial revascularization on survival: a systematic review of studies comparing bilateral and single internal mammary arteries. Lancet. 2001;358:870-5.

7. Gurevitch J, Kramer A, Locker C, Shapira I, Paz Y, Matsa M, et al. Technical aspects of double-skeletonized internal mammary artery grafting. Ann Thorac Surg. 2000;69:841-6.

8. Pevni D, Mohr R, Lev-Ran O, Paz Y, Kramer A, Frolkis I, et al. Technical aspects of composite arterial grafting with double skeletonized internal thoracic arteries. Chest. 2003;123:1348-54.

9. Matsa M, Paz Y, Gurevitch J, Shapira I, Kramer A, Pevny D, et al. Bilateral skeletonized internal thoracic artery grafts in patients with diabetes mellitus. $J$ Thorac Cardiovasc Surg. 2001;121:668-74.

10. Pevni D, Hertz I, Medalion B, Kramer A, Paz Y, Uretzky G, et al. Angiographic evidence for reduced graft patency due to competitive flow in composite arterial T-grafts. J Thorac Cardiovasc Surg. 2007;133:1220-5.

11. Moran SV, Baeza R, Guarda E, Zalaquett R, Irarrazaval MJ, Marchant E, et al. Predictors of radial artery patency for coronary bypass operations. Ann Thorac Surg. 2001;72:1552-6.

12. Roques F, Michel P, Goldstone AR, Nashef SA. The logistic EuroSCORE. Eur Heart J. 2003;24:882-3.

13. Radford MJ, Arnold JM, Bennett SJ, Cinquegrani MP, Cleland JG, Havranek EP, et al. ACC/AHA key data elements and definitions for measuring the clinical management and outcomes of patients with chronic heart failure: a report of the American College of Cardiology/American Heart Association Task Force on Clinical Data Standards (Writing Committee to Develop Heart Failure Clinical Data Standards). Circulation. 2005;112:1888-916.

14. Blackstone E. Comparing apples and oranges. J Thorac Cardiovasc Surg. 2002; 123:8-15.

15. Rehman SH, Yi G, Taggart DP. The radial artery: current concepts on its use in coronary artery revascularization. Ann Thorac Surg. 2013;96:1900-9.

16. Tatoulis J, Buxton BF, Fuller JA. Patencies of 2127 arterial to coronary conduits over 15 years. Ann Thorac Surg. 2004;77:93-101.

17. Ruttmann E, Fischler N, Sakic A, Chevtchik O, Alber H, Schistek R, et al. Second internal thoracic artery versus radial artery in coronary artery bypass grafting: a long-term propensity score-matched follow-up study. Circulation. 2011;124: 1321-9.

18. Manabe S, Fukui T, Shimokawa T, Tabata M, Katayama Y, Morita S, et al. Increased graft occlusion or string sign in composite arterial grafting for mildly stenosed target vessels. Ann Thorac Surg. 2010;89:683-8.

19. Royse AG, Royse CF, Groves KL, Bus B, Yu G. Blood flow in composite arterial grafts and effect of native coronary flow. Ann Thorac Surg. 1999;68: 1619-22.

20. Athanasiou T, Saso S, Rao C, Vecht J, Grapsa J, Dunning J, et al. Radial artery versus saphenous vein conduits for coronary artery bypass surgery: forty years of competition-which conduit offers better patency? A systematic review and meta-analysis. Eur J Cardiothoracic Surg. 2011;40:208-20.

21. Schwann TA, Engoren M, Bonnell M, Clancy C, Habib RH. Comparison of late coronary artery bypass graft survival effects of radial artery versus saphenous vein grafting in male and female patients. Ann Thorac Surg. 2012;94:1485-91. 
22. Tranbaugh RF, Dimitrova KR, Friedmann P, Geller CM, Harris LJ, Steizer P, et al. Coronary artery bypass grafting using the radial artery. Clinical outcomes, patency and need for reintervention. Circulation. 2012;126:S170-5.

23. Tranbaugh RF, Dimitrova KR, Lucido DJ, Hoffmanr DM, Dincheva GR, Geller CM, et al. The second best arterial graft: a propensity analysis of the radial artery versus the free right internal thoracic artery to bypass the circumflex coronary artery. J Thorac Cardiovasc Surg. 2014;147:133-42.

24. Navia D, Vracic M, Piccinini F, Camporrotondo M, Thiere J, Gil C, et al. Is the second internal thoracic artery better than the radial artery in total arterial off-pump coronary artery bypass grafting? A propensity score-matched follow-up study. J Thorac Cardiovasc Surg. 2014;147: 632-8.

25. He GW, Liu ZG. Comparison of nitric oxide release and endothelium-derived hyperpolarizing factor-mediated hyperpolarization between human radial and internal mammary arteries. Circulation. 2001;104(Suppl):S1344-9.

Key Words: revascularization, arterial, BITA, coronary

Readers who found these articles interesting may also like to read the following papers found in recent and future issues of our sister publications, Seminars in Thoracic and Cardiovascular Surgery and Operative Techniques in Thoracic and Cardiovascular Surgery!

\section{Acquired: Coronary Artery Disease}

Original Submissions: Micromorphology of Skeletonized and Pedicled Internal Thoracic and Radial Arteries. Sergey Mamchur. Semin Thorac Cardiovasc Surg 2015; Summer; 27(2):115-120.

Editorial Commentary: Harvesting Arterial Grafts: Barebones or More. Faisal G. Bakaeen. Semin Thorac Cardiovasc Surg 2015; 27(2):121-122. 